Journal of Social Sciences (COES\&RJ-JSS)

ISSN (E): 2305-9249 ISSN (P): 2305-9494

Publisher: Centre of Excellence for Scientific \& Research Journalism, COES\&RJ LLC

Online Publication Date: $1^{\text {st }}$ October 2017

Online Issue: Volume 6, Number 4, October 2017

DOI: $10.25255 /$ jss.2017.6.4.787.801

\title{
The Role of Small and Micro-Enterprises Tourism Projects in Sustainable Economic Growth in Jordan: Madaba as a Case Study
}

\author{
Ibrahim Khalil Bzazao \\ Associate Professor, Dean of the Faculty of Tourism and Hotel Management, \\ University of Jordan, Jordan
}

\author{
Article History: \\ Received Date: $15^{\text {th }}$ September 2016; Revised Date: $15^{\text {th }}$ October 2016; Acceptance Date: \\ $13^{\text {th }}$ November 2016; Publication Date: 1st October 2017
}

\begin{abstract}
:
This research aims to shed light on small projects and their economic effects on the Jordanian economy and to clarify the relationship between the effectiveness of small projects and economic development. Madaba Governorate, with an area of 2,008 $\mathrm{Km} 2$, is located in the mid-southern region of Jordan. The Qasabat Madaba District forms around $42 \%$ of the whole Governorate and its population is currently around 130 thousand persons. In Madaba city, almost all establishments are small; around one third of the businesses are solely owned and half employs two or less employees. Manufacturing establishments have the biggest dimension and trade the smallest. Their products are almost entirely marketed among neighbors and proximate community.
\end{abstract}

Key words:

Small and Micro-Enterprises Projects, Economic Growth, Jordan.

\section{Citation:}

Bzazao, Ibrahim Khalil (2017) ; The Role of Small and Micro-Enterprises Tourism Projects in Sustainable Economic Growth in Jordan: Madaba as a Case Study; Journal of Social Sciences (COES\&RJ-JSS), Vol.6,No.4,pp:787-801; DOI:

10.25255/jss.2017.6.4.787.801. 


\author{
دور المشروعات السياحية الصغيرة والمتتاهية الصغر في تحقيق النمو الإقتصادي المستدام في \\ الأردن: دراسة حالة مادبا فيال

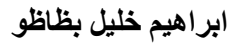 \\ أستاذ مشارك ،عميد كلية السياحة و الفندقة_الجامعة الأردنية ــ الأردن
}

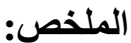

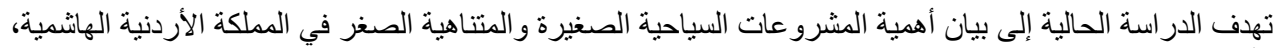

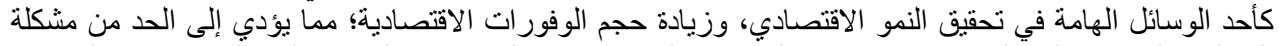

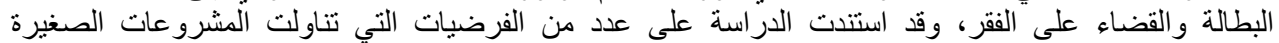

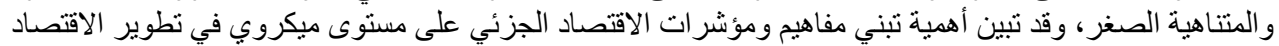

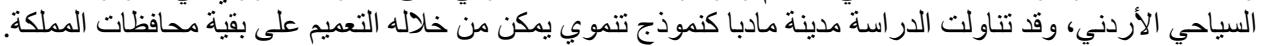

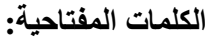

المشاريع الصغيرة، المشاريع المتتاهية الصغر ، السياحة المستدامة، نظام التشبيك، التنمية المتوازنة، الاردن .

مقدمة : مقام

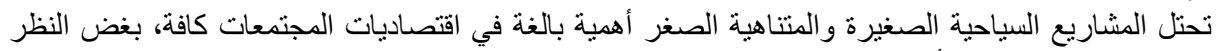

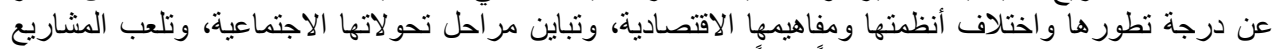

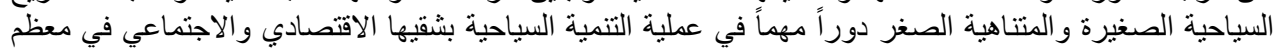

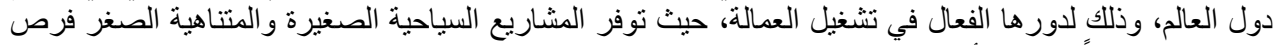

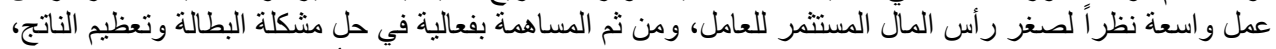

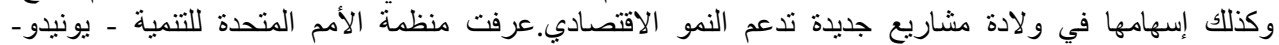

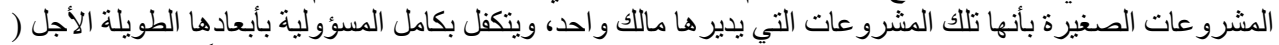

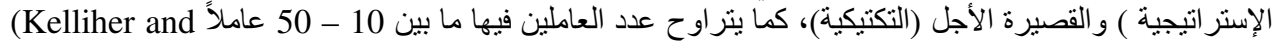

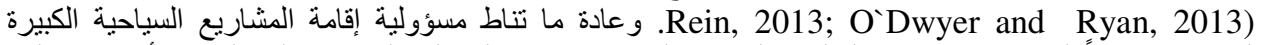

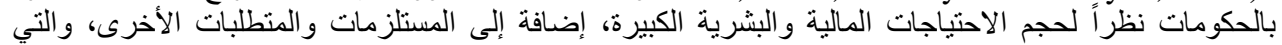

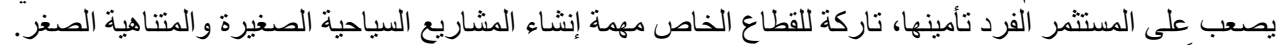

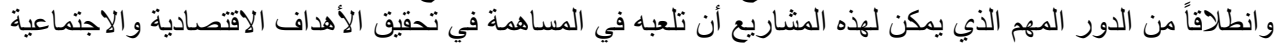

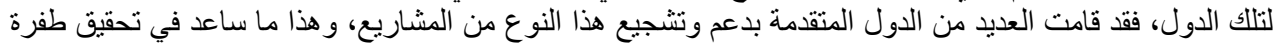

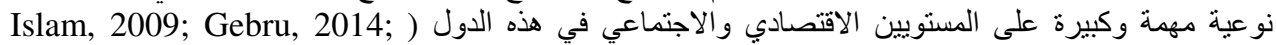
(Greenbank, 2014; Gallina, 2015

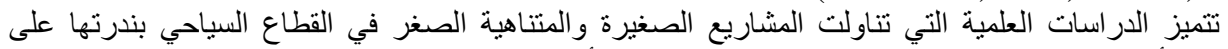

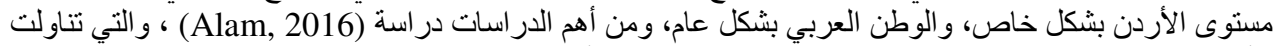

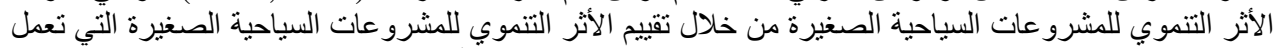

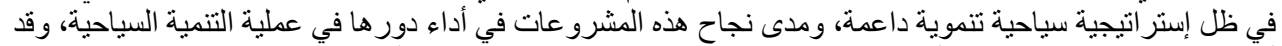

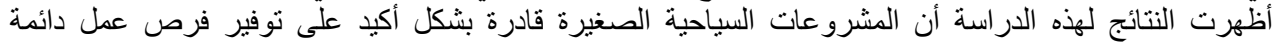

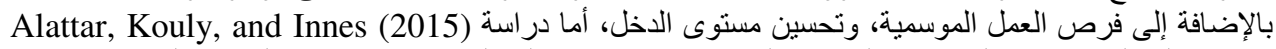

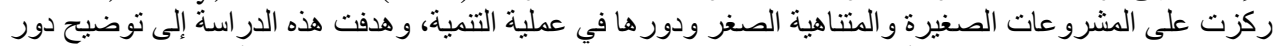

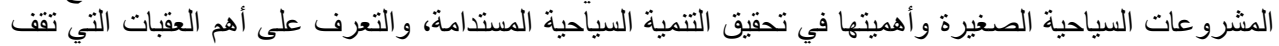

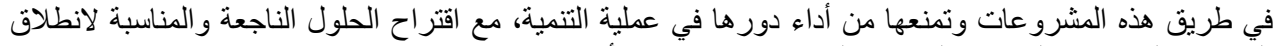

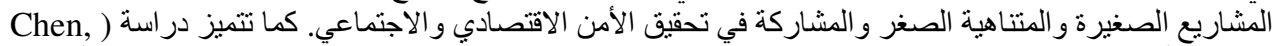

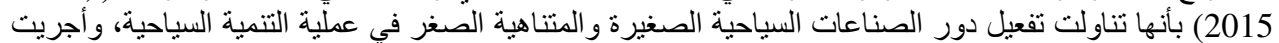

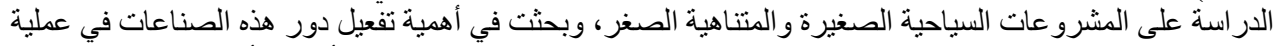

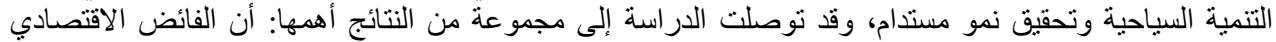

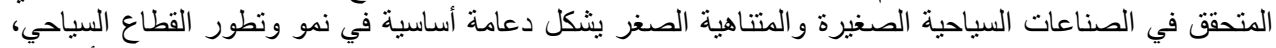
وتوصلت الدر اسة فيما يخص الكفاءة الاقتصادية للصناعات الصغيرة و المتتاهية الصغر تبين مدئ ملاءمتها و أهميتها، وتفوقها على المشرو عات الكبيرة. 


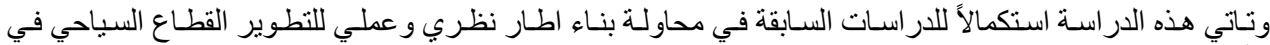

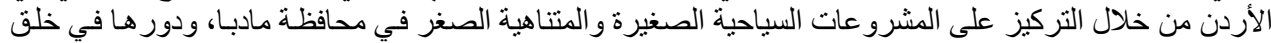
منتج سياحي متنامي ومستدام. أهمية الاراسة

تعد الدراسة من الدراسات القليلة التي تناولت مفاهيم المشاريع السياحية الصغيرة والمتناهية الصغر في المجال

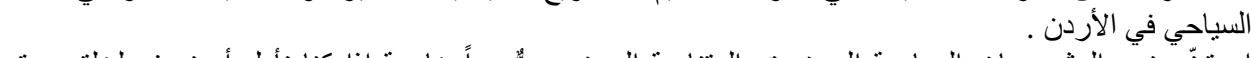

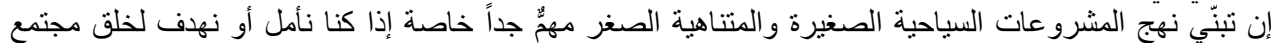

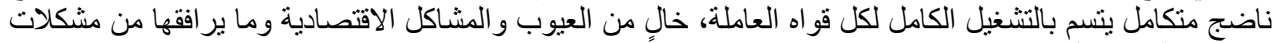

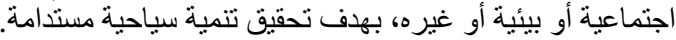

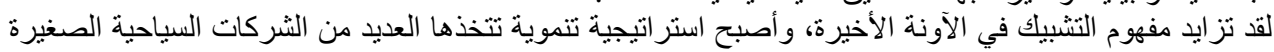

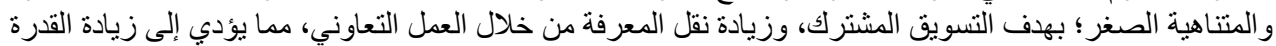

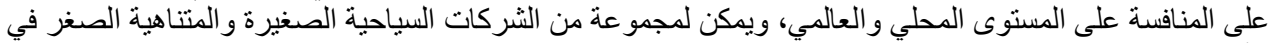

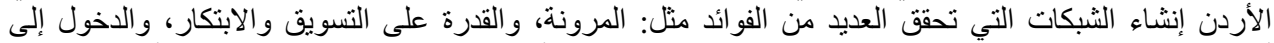

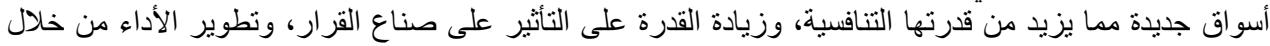
تبادل الخبرات، و الدور المحوري في في تدفق المبلة المعلومات وزيات السياحية. مشكلة الدراسة التئة

يعد العمل ضمن المشروعات السياحية الصغيرة و المتناهية الصغر، وسيلة اقتصادية حديثة تنتاسب مع الدول

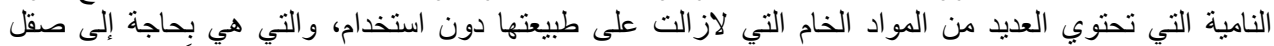

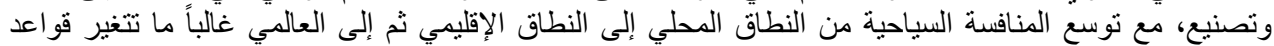

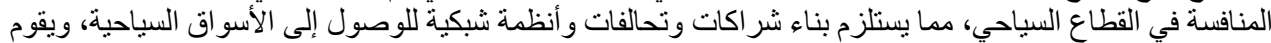

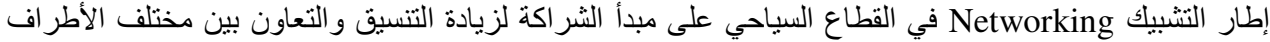

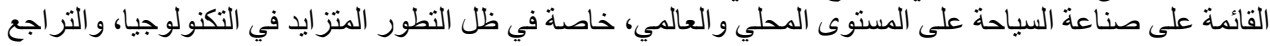

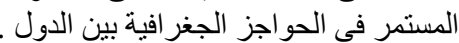

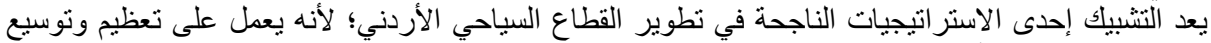

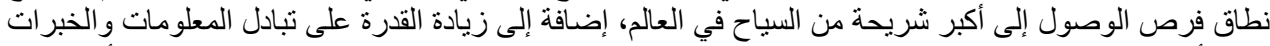

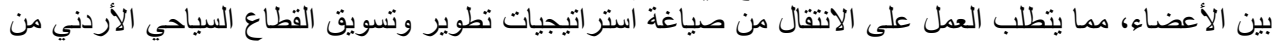

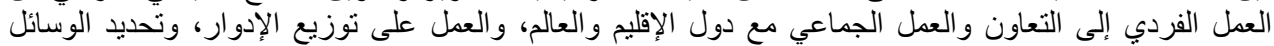

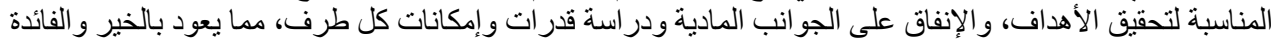

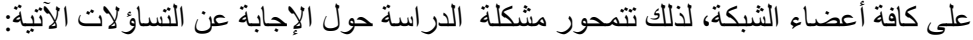

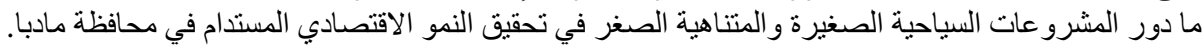

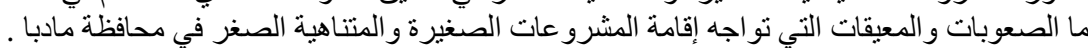

أهداف الاراسة

1- ايجاد حل لمشكلة البطالة المتز ايدة في الأردن بشكل عام، ومحافظة مادبا بشكل خاص، من خلال خلق فرص عمل جديدة .

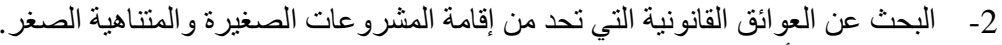

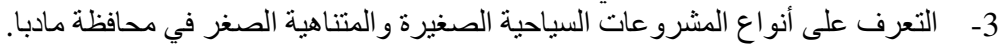

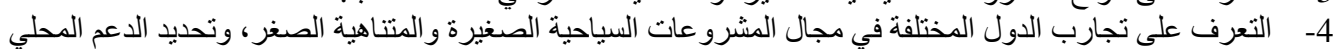

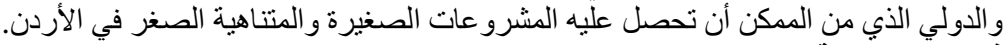
فرضيات الاراسة الفرضية الأولى: المشروعات الصغية الصيرة والمتتاهية الصغر وسيلة فعالة للقضاء على البطالة وتشغيل الثباب وتحقيق

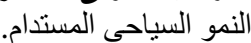
الفرضية الثانية: إن وضع نظام قانوني موحد ومبسط للمشرو عات السياحية الصغيرة و المتناهية الصغر يساهم في استقطاب وتوجيه الاقتصاد الونة الوطني. الفرضية الثالثة: هنالك الكثير من المحنية الكددات القانونية والمالية التي تعيق نمو وتطور المشروعات الصغيرة والمتناهية الصغر في منطقة الدر اسة. 


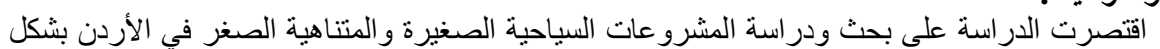

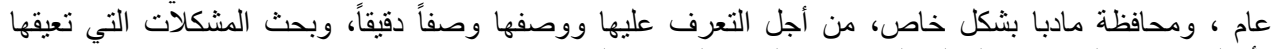

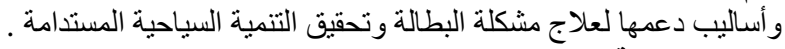

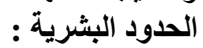

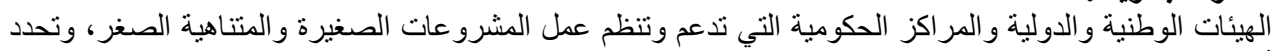

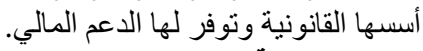
الحدود المكانية : المبنة

المملكة الأردنية الهاشمية ، در اسة حالة محافظة مادبا .

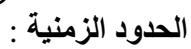

يقتصر هذا البحث على دراسة المشروعات السياحية الصغيرة و المتناهية الصغر خلال الفترة 2000-2016 .

\section{منهجية الدراسة}

تعتمد الدراسة نوعين من المناهج لإيجاد الإطار الثمولي للمشروعات السياحية الصغيرة والمتتاهية

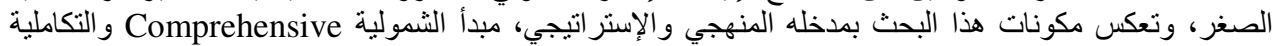

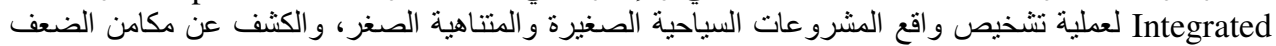

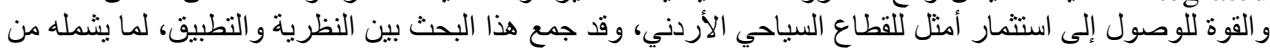

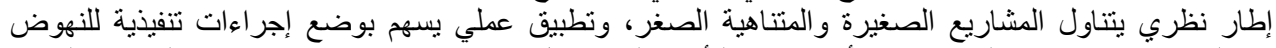

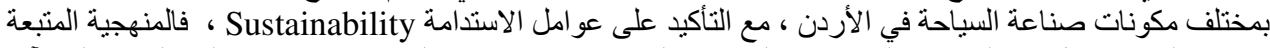

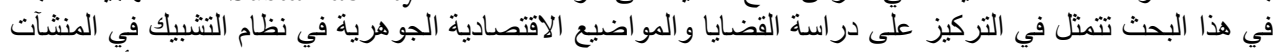

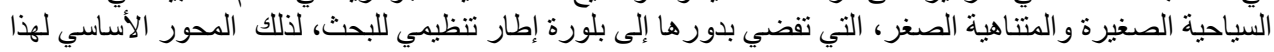

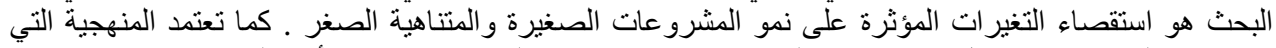

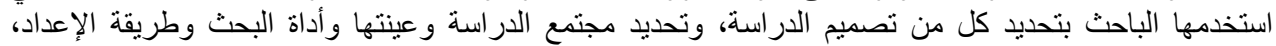
ودلالات الصدق و الثبات، إلى جانب عملية جمع البيانات وتحليلها، ولئ والمعالجات الإحصائية التي استخدمت في التحليل.

تصميم الدراسة الصدن

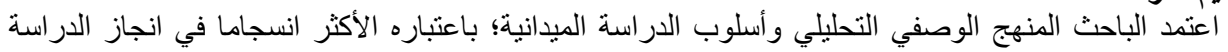

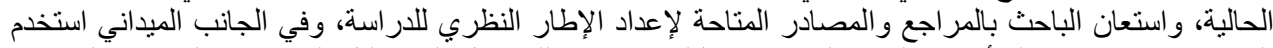

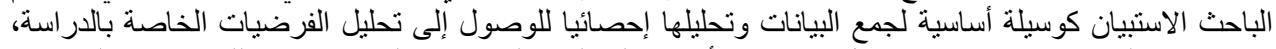

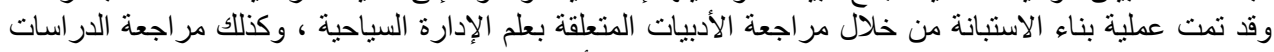

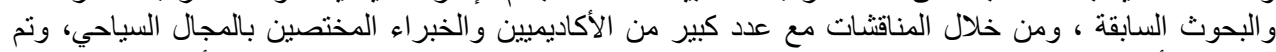

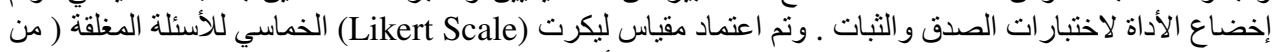

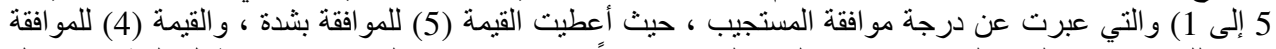

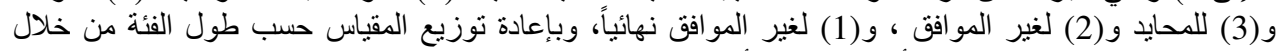

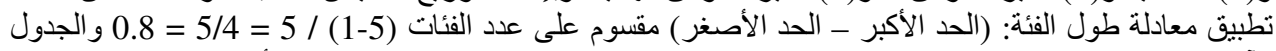

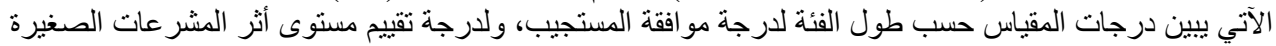

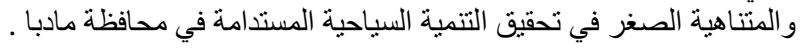

\begin{tabular}{|c|c|c|c|}
\hline تأيقيم الأداء & درجة الموافة & âtill & القيمة في المقياس \\
\hline مستوى أداء منخفض جداً & غير مو افق نهائياً & $1-1.8$ & 1 \\
\hline مستوى أداء منخفض & غير مو افق & $2.6-1.81$ & 2 \\
\hline مستوى أداء متوسط & محايد & $3.4-2.61$ & 3 \\
\hline مستوى أداء مرتفع & مو افق & $4.2-3.41$ & 4 \\
\hline مستوى أداء مرتفع جدا & مو افق بشدة & $5-4.21$ & 5 \\
\hline
\end{tabular}

أما الأسئلة المفتوحة فقد اعتمد الباحث على أسلوب التكرار ات في حصر إجابة الفئات الفرعية لمجتمع الدراسة .

اختبار الصدق والثبات أبنات

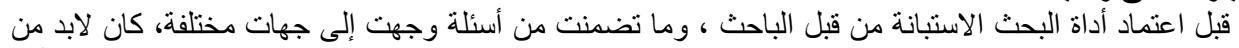

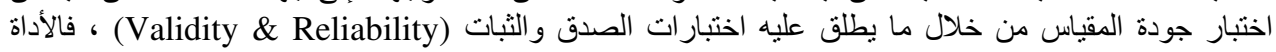




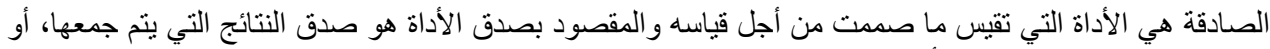

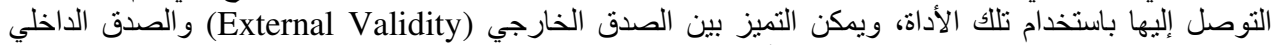

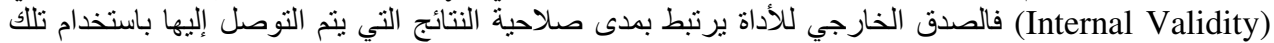

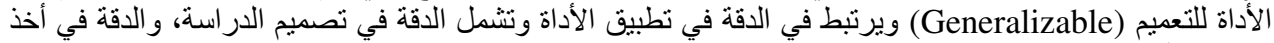

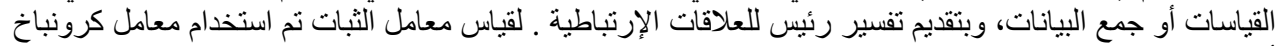

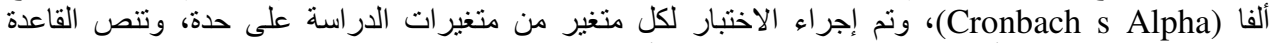

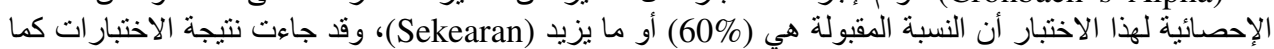

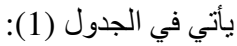

الجدول (1) نتائج اختبار كرونباخ ألفا لاستبانة الدر اسة

\begin{tabular}{|c|c|c|c|}
\hline قيمة المعامل & الفرعية & المتغيرات الرئيسة & \\
\hline 0.804 & 5 & الشكاليات إنشاء المشاريع السياحية الصغيرة والمتتاهية & 1 \\
\hline 0.821 & 3 & تمكين العاملين في المشاريع الصغيرة و المتتاهية الصغر & 2 \\
\hline 0.832 & 5 & والمشروعات الصغيرة وسيلة فعالة للقضاء على البطالة & 3 \\
\hline
\end{tabular}

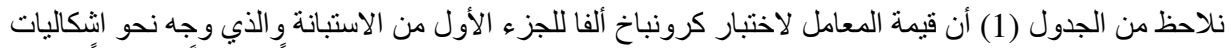

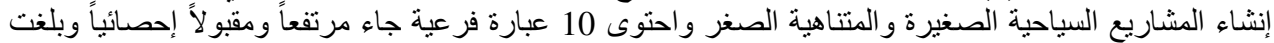

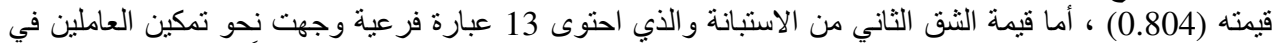

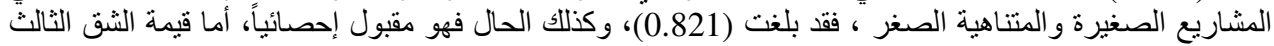

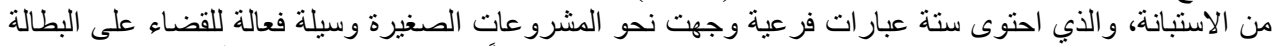

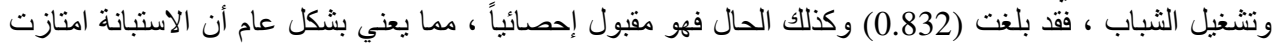
بدرجة صدق وثبات عالية .

أساليب التحليل الإحصائي الاحي

تمت عملية التحليل الإحصائي باستخدام برنامج الحزم الإحصائية (SPSS) وتم استخدام أدوات الإحساء الإحساء الوصفي

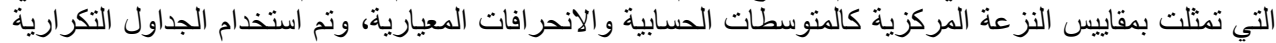
إضنافة إلى :

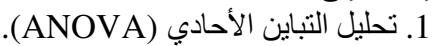

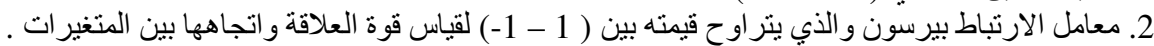

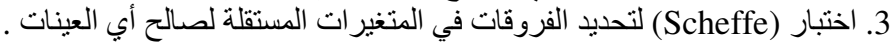
4. تحليل الانحدار 5. معامل كرونباخ ألفا (Cronbach s Alpha)، لقياس ثبات وصدق أداة القياس .

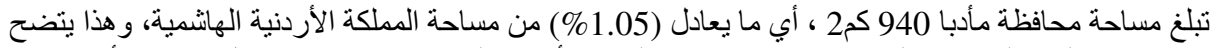

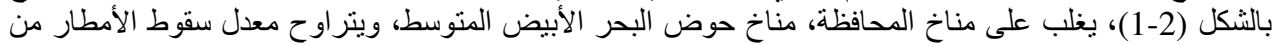

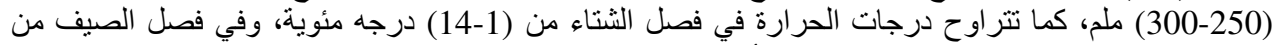

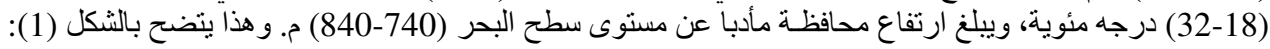




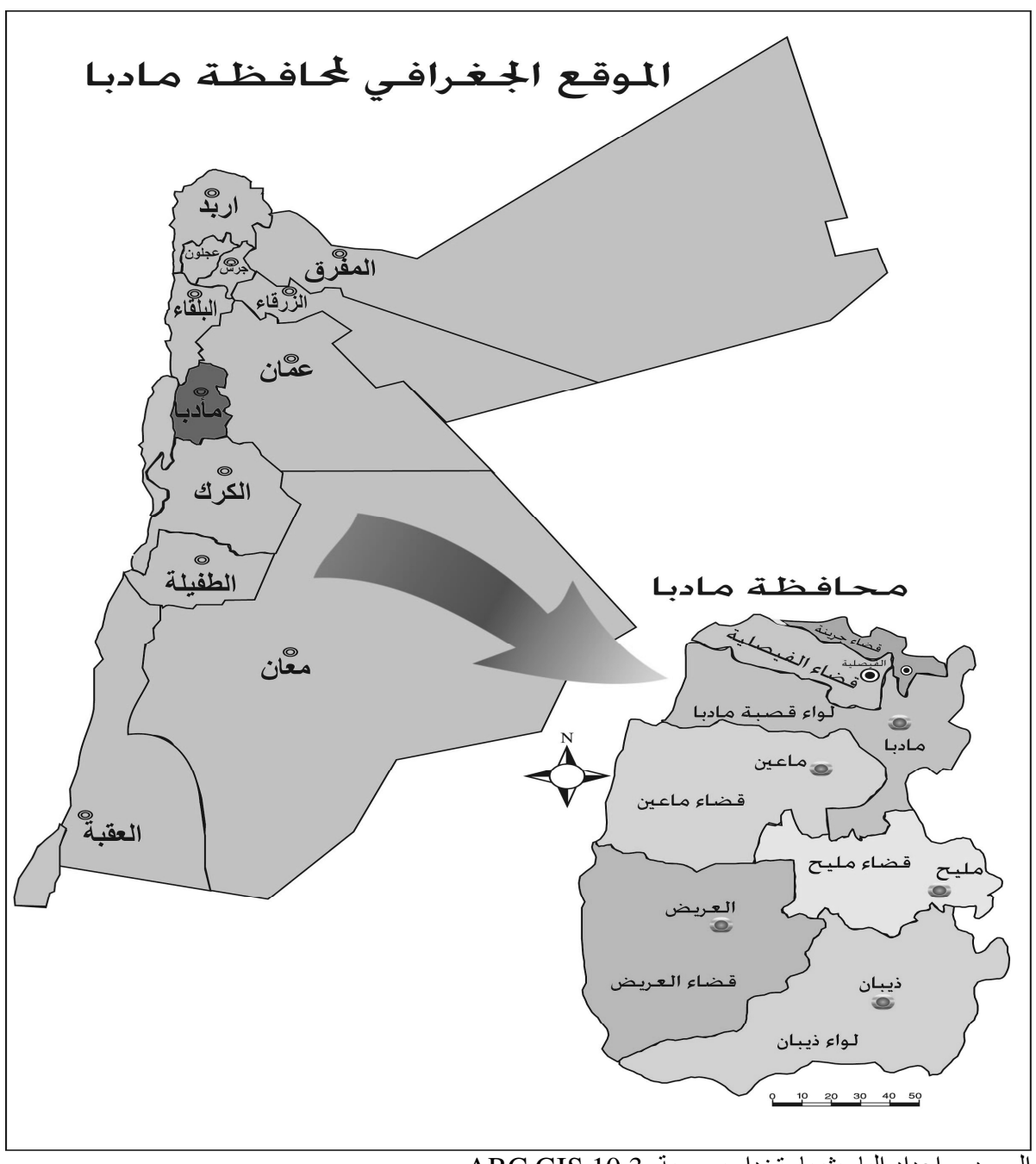

ARC GIS 10.3 المصدر: اعداد الباحث باستخدام برمجية

نظام التشبيك في المشاريع السياحية الصغيرة والمتناهية الصغر

لقد تزايد مفهوم التشبيك في الآونة الأخيرة، وأصبح استراتيجية تنموية تتخذها العديد من الثركات الصغيرة

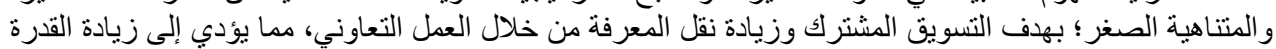

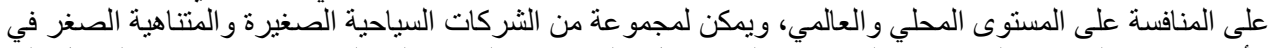

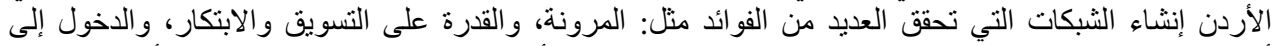

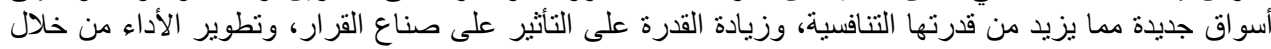

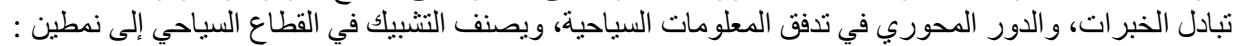

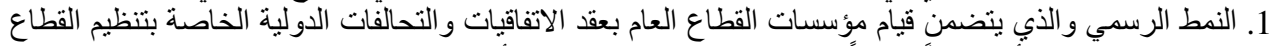

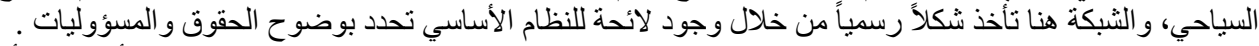

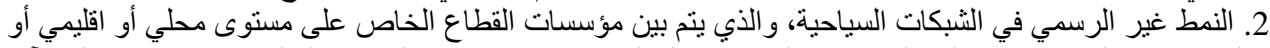

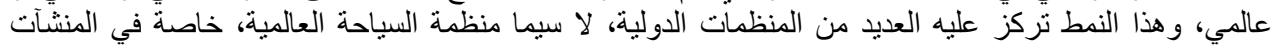

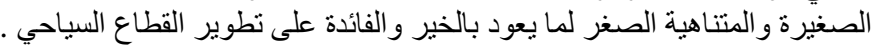




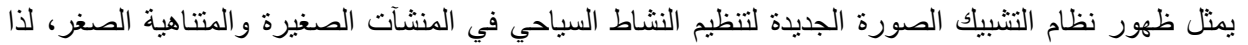

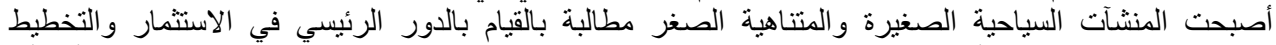

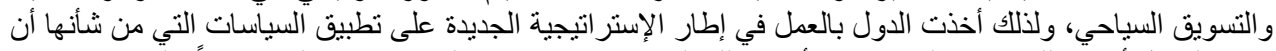

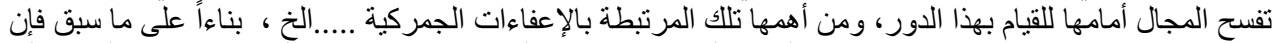

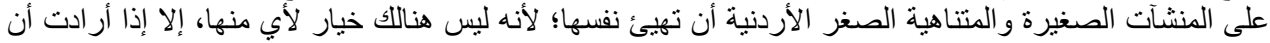
تصبح خارج المنافسة السياحية الدولية.

فوائد تبني مفهوم التشبيك في المنشآت الصغيرة والمتناهية الصغر في القطاع السياحي الأردني

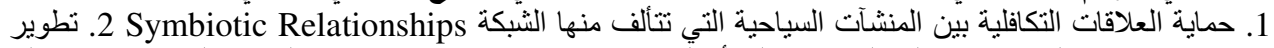

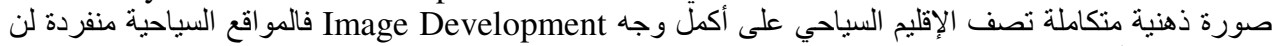

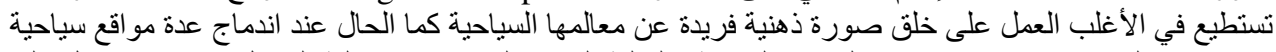

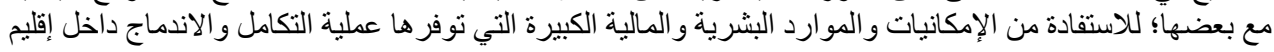
سياحي واحد.

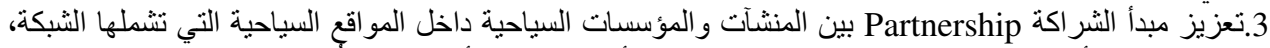

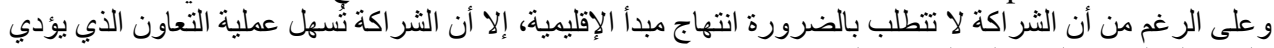

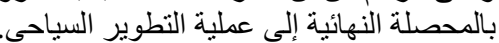

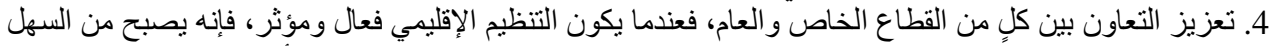

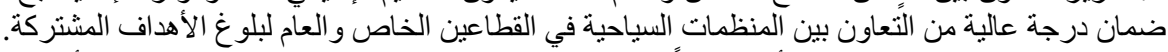

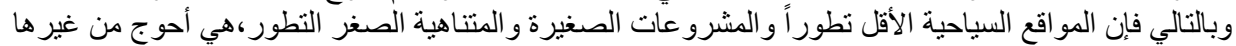

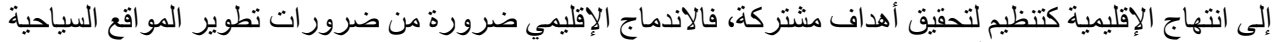

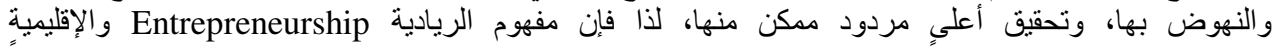
Regionalization للانتشار و التوسع في صناعة السياحة.

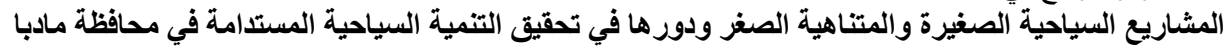

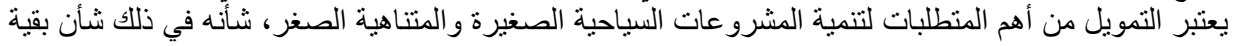

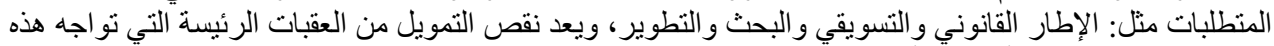

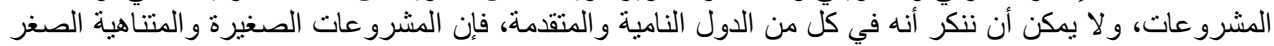

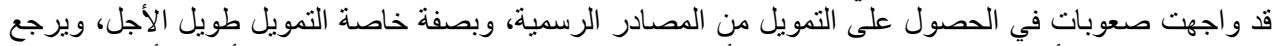

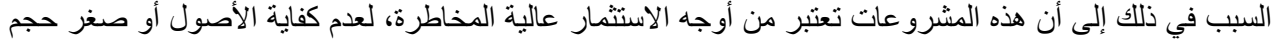

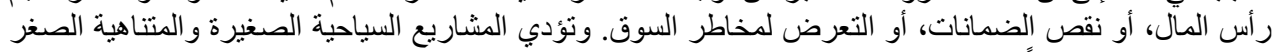

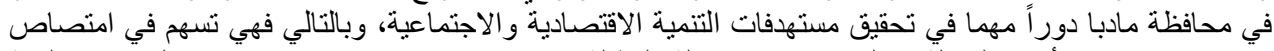

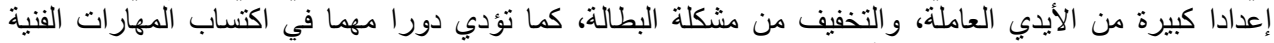

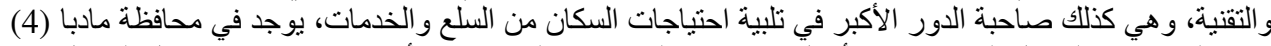

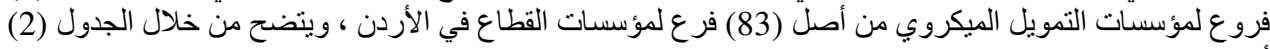
أبرز مؤشر اتها لمؤبنات 


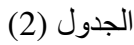

\begin{tabular}{|c|c|c|c|c|c|c|}
\hline \multicolumn{2}{|c|}{ عدد الفروع } & \multicolumn{2}{|c|}{ حسجم التهويل } & \multicolumn{2}{|c|}{ عدد المستفيدين } & \multirow{2}{*}{ اسـم المؤســـة } \\
\hline المملكة & مادبا & المملكة & 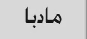 & المملكة & 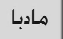 & \\
\hline 10 & 1 & 62975466 & 3395431 & 92859 & 5270 & البنك الوطني لنمويل المشـاريع الصفيرة NBA \\
\hline 22 & 1 & 14311062 & 750522 & 56646 & 3136 & MFW شركة صندوق المرأة \\
\hline 17 & 1 & 13497602 & 966867 & 57102 & 3387 & الشـركة الأردنبة لنموبل المشـاريع الصـفيرة \\
\hline 13 & 1 & 13987337 & 693995 & 11189 & 867 & شـركة الشـرق الأوسـط لتمويل المشـاريع الصغيرة \\
\hline 8 & --. & 6277730 & --- & 6918 & $\cdots$ & الشـركة الأهلية لتنمبية وتمويل المشاريع الصغيرة \\
\hline 7 & $\cdots$ & 5.872933 & $\cdots$ & 1.842 & $\cdots$ & الشركة المتخصصة للقروض الصغيرة فينكا \\
\hline 2 & --- & 1437241 & --- & 3210 & --- & شـركة الأمين لتهويل المشاريع الصغيرة \\
\hline 4 & -- & 29.357 .600 & $\cdots$ & 5770 & --- & 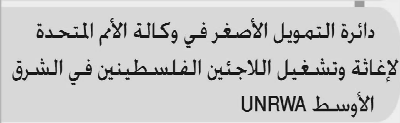 \\
\hline 12 & 1 & 7983265 & 116439 & 5743 & 116 & شركة بنك القاهرة عمان \\
\hline 83 & 4 & 155700236 & 5923254 & 250216 & 12776 & الجمهموع \\
\hline
\end{tabular}

المصدر : اعداد الباحث اعتماداً على بيانات وزارة التخطيط لعام 2016

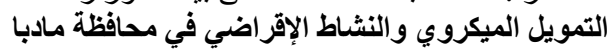

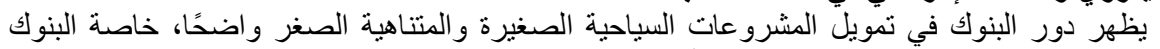

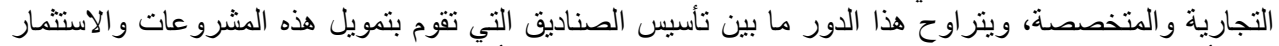
فيها، أو إنشاء وحدات خاصة داخل البنوك لتمويل هذه المشروعات، وتأخذ الخدمات التمويلية التي تقدمها البنوك لهذه

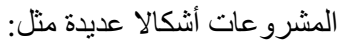

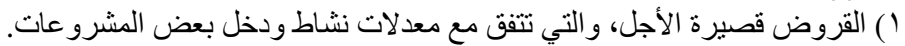

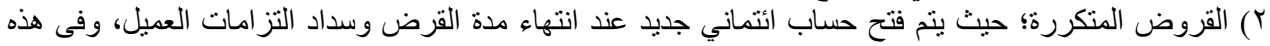

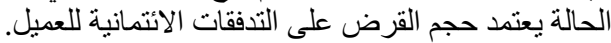

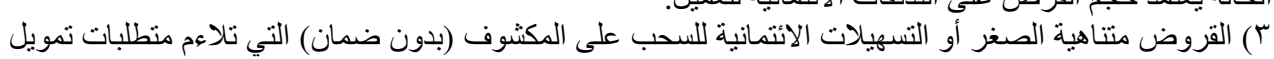

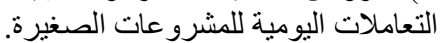

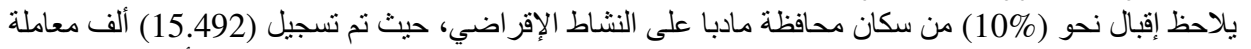

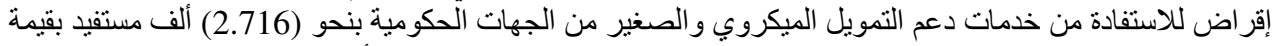

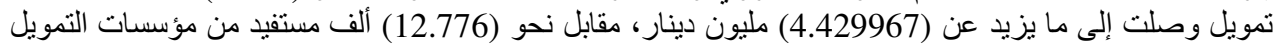

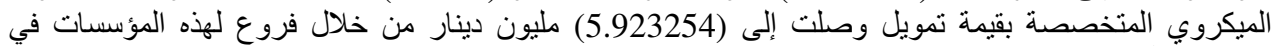
المحافظة (وزارة المالية ، 2012 ، النشرة الإحصنئية وصنية السنوية).

خصائص المشروعات الصغيرة والمتناهية الصغر

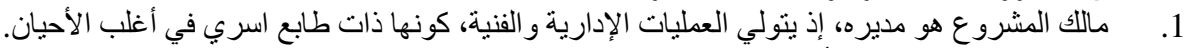

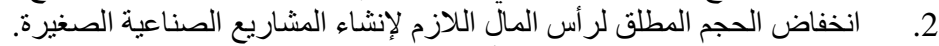

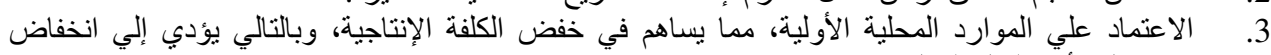

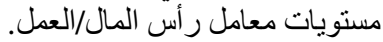
4. تدني قدر اتها الذاتية علي التطور والتوسع؛ نظر الإهمال جوانب البحث والتطوير، وعدم الاقتتاع بأهميتها

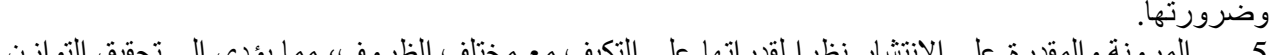
في العملية الإنتاجية. 6. ي قصعوبة العمليات التسويقية و التوزيعية، نظر الارتفاع كلفة هذه العمليات/ و عدم قدرتها على تحمل مثل هذه 
10. الافتقار إلى هيكل إداري، كونها تدار من قبل شخص واحد مسئول إداريا وماليا وفنيا.

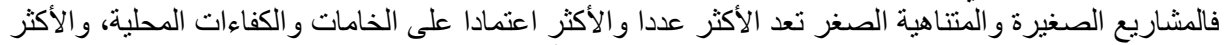

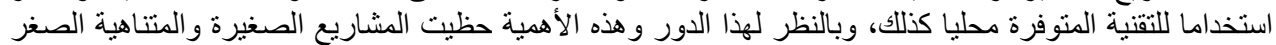

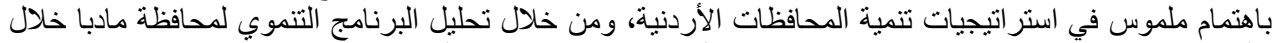

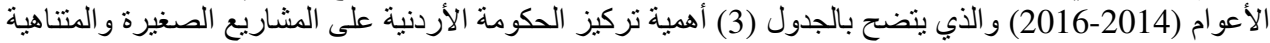

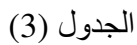

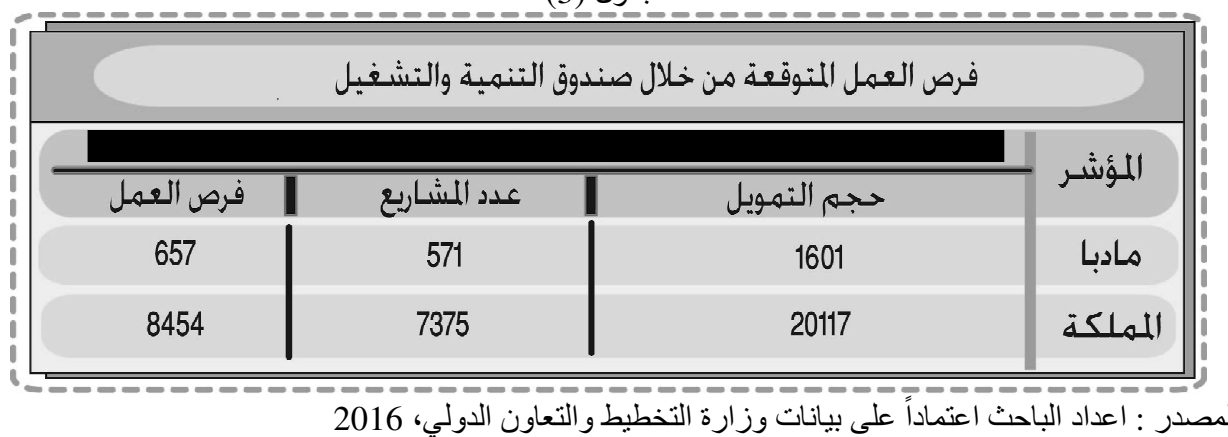

\begin{tabular}{|c|c|c|c|}
\hline \multicolumn{4}{|c|}{ مؤسـسـات التمويل الميكروي المتخـصصة في مـحافظة مادبا } \\
\hline حجــ التمويل & عدد المستفيدين & عدد الفروع & المؤشـر \\
\hline 5923254 & 12776 & 4 & مادبا \\
\hline 155700236 & 250216 & 83 & المملكة \\
\hline
\end{tabular}

و لإقامة المشرو عات الصغيرة و المتناهية الصغر أهمية كبيرة في محافظة مادبا، وبالأخص في مجال التنمية السياحية ،

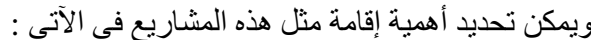

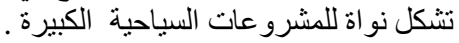

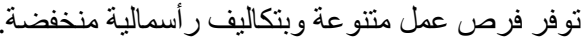

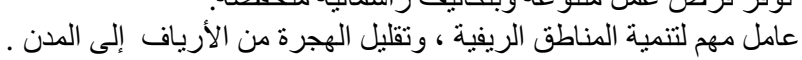

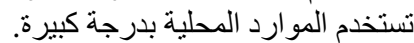

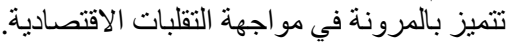
دعم سياسات الاكتفاء الذاتي على الأقل في بعض الأفئ السلع و الخدمات و التقليل من الاستير اد وتحسين الصادرات و المساهمة الفعلية في دعم الناتج التقومي.

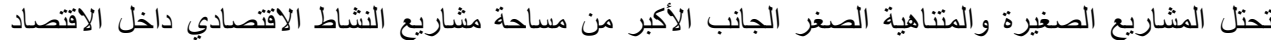

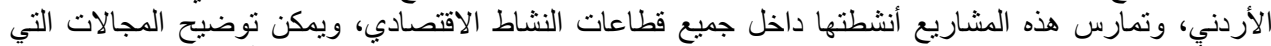

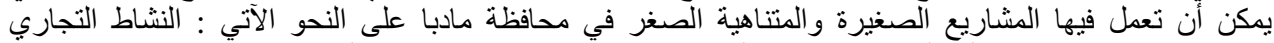

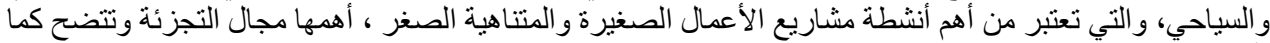

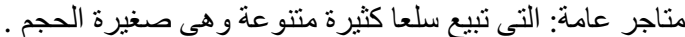

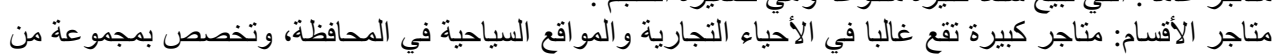

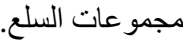
ت 


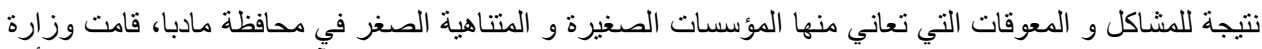

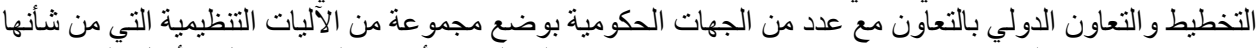

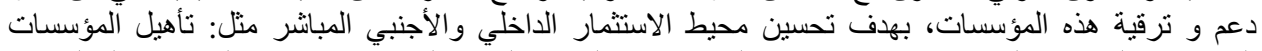

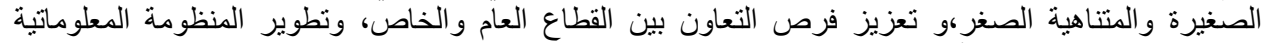

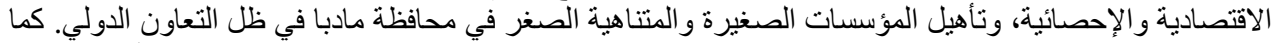

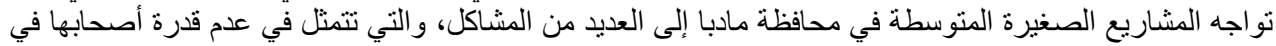

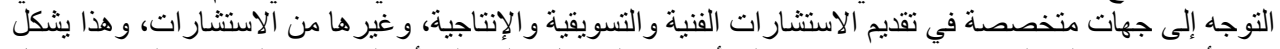

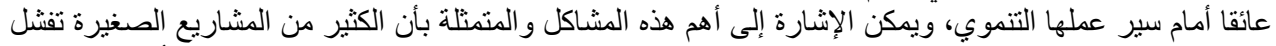

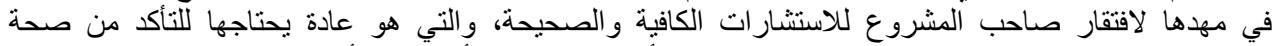

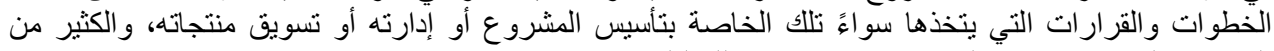

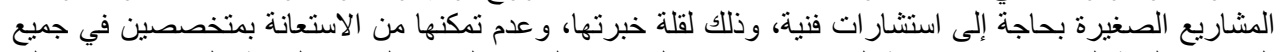

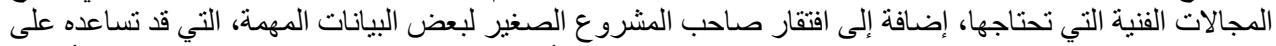

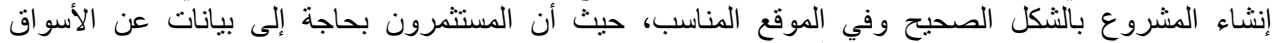

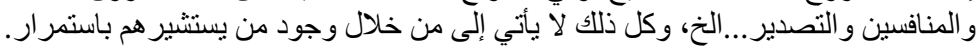

\section{اختبار الفرضيات}

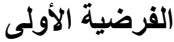

: لا توجد فروق ذات دلالة إحصائية في المتوسطات الحسابية لمدى توفر المشاريع السياحية الصغيرة و المتتاهية

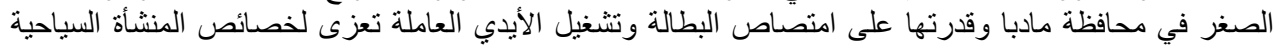

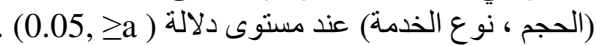

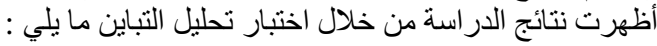

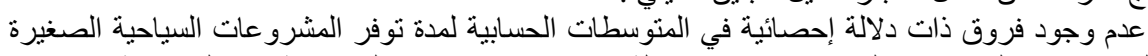

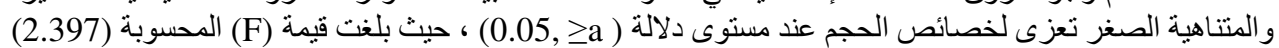

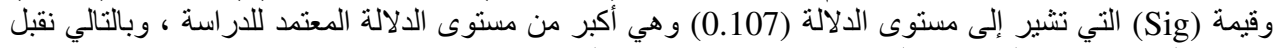

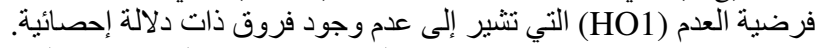

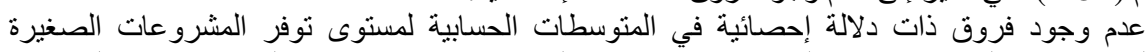

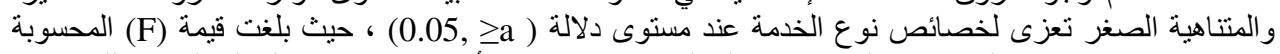

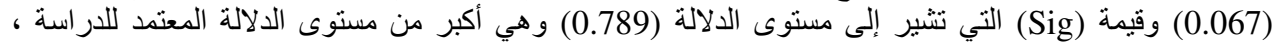

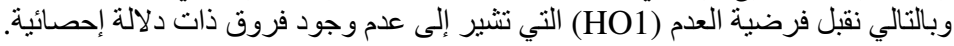

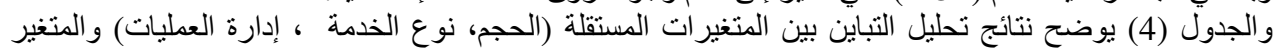

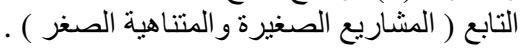

(4) الجدول

\begin{tabular}{|c|c|c|c|c|c|}
\hline Sig & $\mathbf{F}$ & درجات الحرية & مجموع المربعات & & المتغير \\
\hline \multirow[t]{3}{*}{0.107} & 2.487 & 2 & 2.747 & بين المجمو عات & \multirow[t]{3}{*}{ الحجم } \\
\hline & & 32 & 18.582 & ضمن المجمو عات & \\
\hline & & 34 & 21.338 & المجموع & \\
\hline \multirow[t]{3}{*}{0,797} & 0.067 & 1 & .041 & بين المجمو عات & \multirow{3}{*}{ الخدمة } \\
\hline & & 33 & 20.186 & ضمن المجمو عات & \\
\hline & & 34 & 20.227 & المجموع & \\
\hline \multirow[t]{3}{*}{0.008} & 7.858 & 1 & 3.890 & بين المجمو عات & \multirow[t]{3}{*}{ التخطيط } \\
\hline & & 33 & 16.337 & ضمن المجمو عات & \\
\hline & & 34 & 20.227 & المجموع & \\
\hline \multirow[t]{3}{*}{0.034} & 4.865 & 1 & 2.599 & بين المجمو عات & \multirow{3}{*}{ العمليات } \\
\hline & & 33 & 17.628 & ضمن المجمو عات & \\
\hline & & 34 & 20.227 & المجموع & \\
\hline
\end{tabular}


The Role of small and micro.........

الجدول (5) نتائج اخبار شافييه لعامل التشغيل في المشرو عات الصغيرة والمتناهية الصغر في مادبا

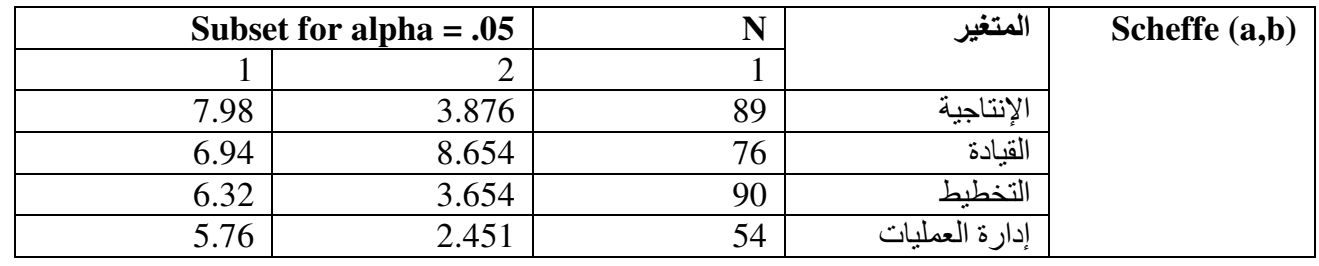

الفرضية الرئيسة الثانية

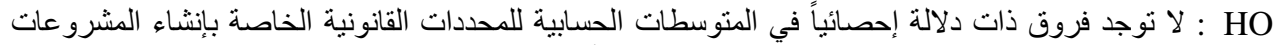

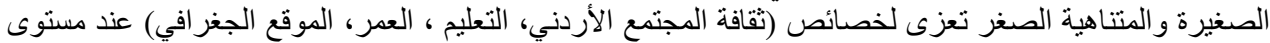
دلالة (0.05, (0.0) . أظهرت نتائج الدراسة من خلال اختبار تحليل التباين ما يلي :

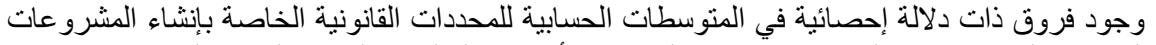

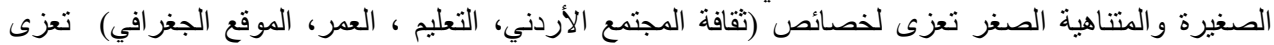

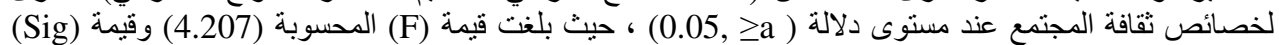

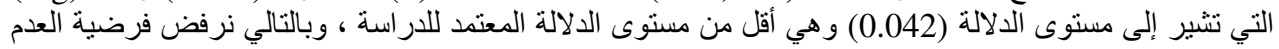

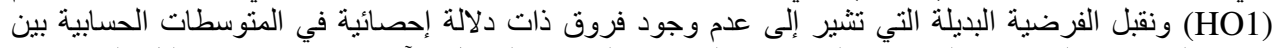

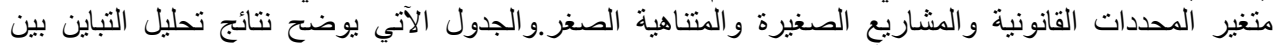

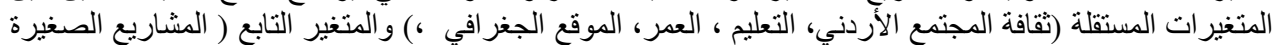

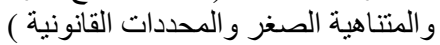

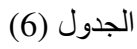

\begin{tabular}{|c|c|c|c|c|c|}
\hline Sig & $\mathbf{F}$ & درجات الحرية & مجموع المربعات & & المتغير \\
\hline \multirow[t]{3}{*}{0.042} & 4.207 & 1 & 1.339 & بين المجمو عات & \multirow[t]{3}{*}{ القوانين } \\
\hline & & 198 & 63.028 & ضمن المجمو عات & \\
\hline & & 199 & 64.367 & المجموع & \\
\hline \multirow[t]{3}{*}{0.000} & 12.109 & 7 & 19.713 & بين المجمو عات & \multirow[t]{3}{*}{ التعليم } \\
\hline & & 192 & 44.654 & ضمن المجمو عات & \\
\hline & & 199 & 64.367 & المجموع & \\
\hline \multirow[t]{3}{*}{0.256} & 1.361 & 3 & 1.314 & بين المجمو عات & \multirow{3}{*}{ الاستثمار } \\
\hline & & 196 & 63.054 & ضمن المجمو عات & \\
\hline & & 199 & 64.367 & المجموع & \\
\hline \multirow[t]{3}{*}{0.037} & 2.606 & 4 & 3.266 & بين المجمو عات & \multirow[t]{3}{*}{ البنوك } \\
\hline & & 195 & 61.101 & ضمن المجمو عات & \\
\hline & & 199 & 64.367 & المجموع & \\
\hline
\end{tabular}

النتائج

1- تو اجه المشاريع السياحية الصغيرة و المتناهية الصغر مشكلة التشدد في طلب الضمانات من قبل الجهات المانحة ،

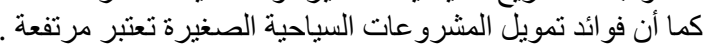

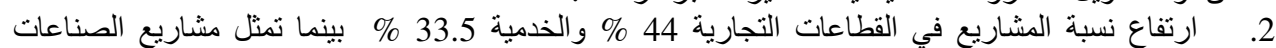
الحرفية السياحية 10.5 \% وذللك راجع لأن أغلب المشاريع عبارة عن مشاريع فردية وتمول بمدخر ات شخصية وهي لاتحتاج إلى رأس مال قوي.

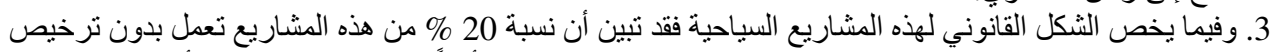

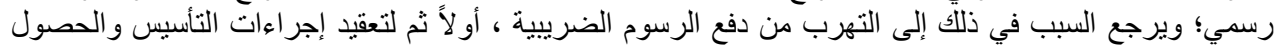

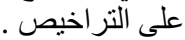


4. تصنف المشاريع السياحية في محافظة مادبا بأنها 70 \% منها مصنفة رسمياً على أنها مشاريع صغيرة بينما كانت 30

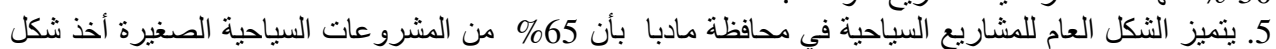

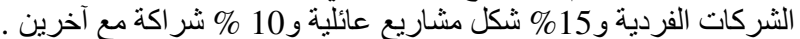

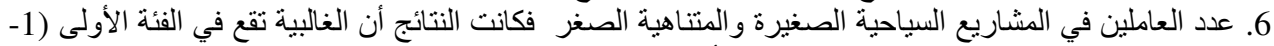

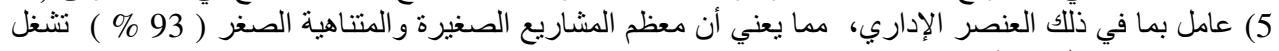

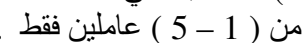

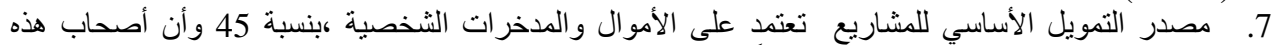

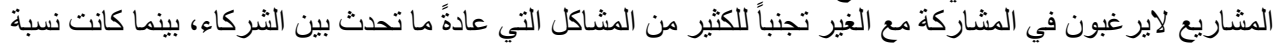

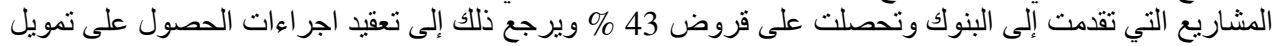
من المصرف وإيع التى صغر قيمة القرض.

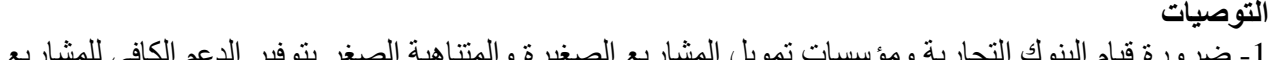

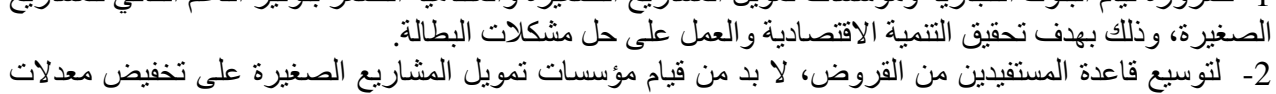

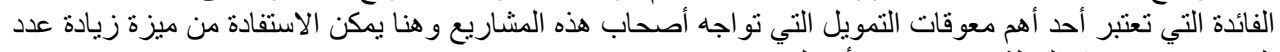

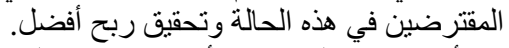

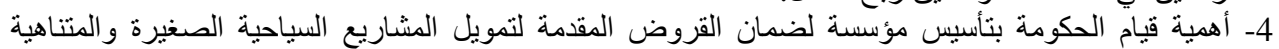

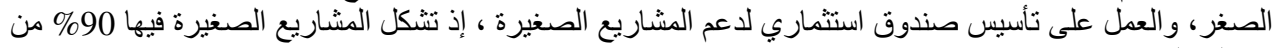
إجمالي المشاريع الاقتصلئ تادية.

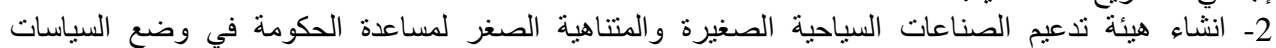

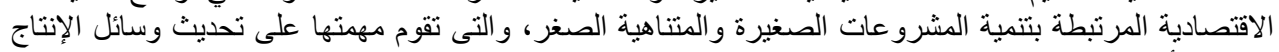

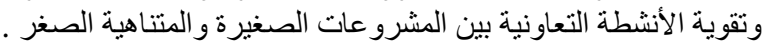

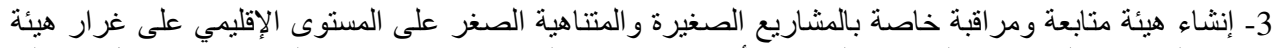

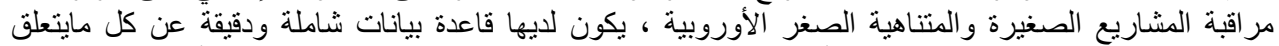

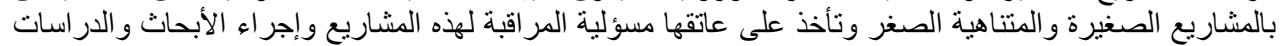

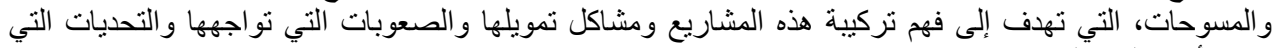
ينبغي أن تتغلب عليها. 4- وحيث أن بعض الباحثين ) 2012, 2013; Shannak et al., 2010; Masa'deh et al., 2008, 2013, 2014, 2015, 2017; Hajir et (al., 2015; Kateb et al., 2015; Obeidat et al., 2016; Vratskikh et al., 2016

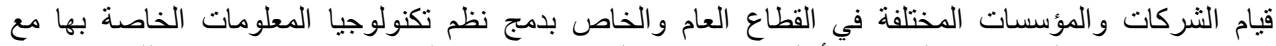

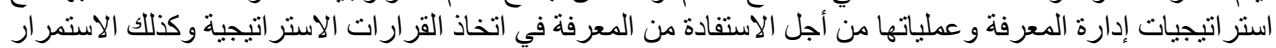

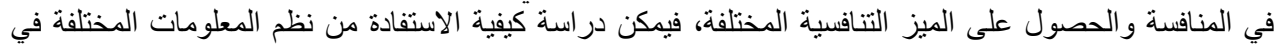
التنبؤ من مخاطر التطرف والار هاب و الاحداث الامنية و السياسية على القطاعات السياحية المختلفة.

\section{References}

Alam, M. (2016). A Comparative Study of Financing Small and Cottage Industries by Interest - Free Banks in Turkey, Cyprus, Sudan and Bangladesh. Humanomics, 24 (2), $145-161$.

Alattar, J., Kouly, R., and Innes, J. (2015). Management Accounting Information in Micro Enterprise in Gaza. Journal of Accounting and Organizational Change, 5 (1), 81-107.

Altamony, H., Alshurideh, M., and Obeidat, B. (2012), Information Systems for Competitive Advantage: Implementation of an Organizational Strategic Management Process. Proceedings of the 18th IBIMA Conference on Innovation and Sustainable Economic Competitive Advantage: From Regional Development to World Economic, Istanbul, Turkey, 9th-10th May. 
Chen, J. (2015). Development of Chinese Small and Medium Sized Enterprises. Journal of Small Business and Enterprise Development, 13 (2), 140-147.

Gallina, A. (2015). SME Contribution to the Creation of the Euro-Mediterranean Region. ERF Working Paper No. 0106, Cairo: Economic Research Forum for Arab Countries, Iran and Turkey (ERF).

Gebru, G. (2014). Financing Preference of Micro and Small Enterprise Owners in Tigroy: Does POH Hold?. Journal of Small Business and Enterprise Development, 16 (2), 322334.

Greenbank, P. (2014). Training Micro Business Owner-Managers: A Challenge to Current Approach. Journal of European Industrial Training, 24 (7), 403-411.

Hajir, J., Obeidat, B., and Al-dalahmeh, M. (2015), The Role of Knowledge Management Infrastructure in Enhancing Innovation at Mobile Telecommunication Companies in Jordan, European Journal of Social Sciences, 50 (3), 313-330.

Islam, S. (2009). Start-Up and Growth Constraints on Small-Scale Trading in Bangladesh. Journal of Chinese Entrepreneurship, 1 (3), 227-239.

Kateb, M., Swies, R., Obeidat, B., and Maqableh, M. (2015), An Investigation on the Critical Factors of Information System Implementation in Jordanian Information Technology Companies, European Journal of Business and Management, 7 (36), 11-28.

Kelliher,R., and Rein, L. (2013). A Resource-Based View of Micro-Firm Management Practice. Journal of Small Business and Enterprise Development, 13 (3), 521-532.

Masa'deh, R. (2012), The Impact of Management Information Systems (MIS) on Quality Assurance (QA): A Case Study in Jordan, International Journal of Information, Business, and Management, 93-110.

Masa'deh, R. (2013), The Impact of Information Technology Infrastructure Flexibility on Firm Performance: An Empirical Study of Jordanian Public Shareholding Firms, Jordan Journal of Business Administration, 204-224.

Masa'deh, R., and Shannak, R. (2012), Intermediary Effects of Knowledge Management Strategy and Learning Orientation on Strategic Alignment and Firm Performance, Research Journal of International Studies, 112-128 .

Masa'deh, R., Gharaibeh, A., Maqableh, M., and Karajeh, H. (2013), An Empirical Study of Antecedents and Outcomes of Knowledge Sharing Capability in Jordanian Telecommunication Firms: A Structural Equation Modeling Approach, Life Science Journal, 10 (4), 2284-2296.

Masa'deh, R., Gharaibeh, A., Tarhini, A., and Obeidat, O. (2015), Knowledge Sharing Capability: A Literature Review. In Fourth Scientific \& Research Conference on New Trends in Business, Management and Social Sciences, Istanbul, Turkey, 19-20 September 2015, 1-16. 
Masa'deh, R., Hunaiti, Z., and Bani Yaseen, A. (2008), An Integrative Model Linking ITBusiness Strategic Alignment and Firm Performance: The Mediating Role of Pursuing Innovation and Knowledge Management Strategies, Communications of the International Business Information Management Association (IBIMA) Journal, 2 (24), 180-187.

Masa'deh, R., Maqableh, M., and Karajeh, H. (2014), A Theoretical Perspective on the Relationship between Leadership Development, Knowledge Management Capability, and Firm Performance, Asian Social Science, 10 (6), 128.

Masa'deh, R., Shannak, R., Maqableh, M., and Tarhini, A. (2017), The Impact of Knowledge Management on Job Performance in Higher Education: The Case of the University of Jordan, Journal of Enterprise Information Management, 30 ( 2), 244-262.

Obeidat, B., Al-Suradi, M., Masa'deh, R., and Tarhini, R. (2016), The Impact of Knowledge Management on Innovation, Management Research Review, 39 (10), 12141238.

O`Dwyer, M., and Ryan, E. (2013). Management Development Issues for Owners/Managers of Micro Enterprise. Journal of European Industrial Training, 24 (6), 345-353.

Shannak, R., Obeidat, B., and Almajali, D. (2010), Information Technology Investments: A Literature Review. Proceedings of the 14th IBIMA Conference on Global Business Transformation through Innovation and Knowledge Management: An Academic Perspective, Istanbul-Turkey, 23rd-24th June, 1356-1368.

Vratskikh, I., Al-Lozi, M., and Maqableh, M. (2016), The Impact of Emotional Intelligence on Job Performance via the Mediating Role of Job Satisfaction, International Journal of Business and Management, 11 (2), 69-91. 